\title{
Photocatalytic Cycloaddition Reaction of Triarylphosphines with Alkynes Forming Cyclic Phosphonium Salts
}

\author{
Yusuke Masuda, ${ }^{\dagger}$ Daichi Ikeshita, and Masahiro Murakami* \\ Department of Synthetic Chemistry and Biological Chemistry, Kyoto University, Katsura, Kyoto 615-8510, Japan \\ ${ }^{\dagger}$ Present address: Department of Chemistry, Faculty of Science, Hokkaido University, Kita-ku, Sapporo, Hokkaido 060-0810, Japan.
}

E-mail: murakami@sbchem.kyoto-u.ac.jp

1 Herein reported is a photocatalytic cycloaddition 2 reaction of triarylphosphines with alkynes. Phosphonium 3 salts of unique bicyclic structures are synthesized through a 4 radical pathway under mild reaction conditions. The 5 phosphonium salts are subjected to the Wittig olefination 6 reaction to afford structurally interesting phosphine oxides.

7 Keywords: Phosphonium salt • Alkyne - Photoredox 8 catalyst

Phosphonium salts belong to an important class of compounds that are utilized as synthetic reagents, ${ }^{1}$ organocatalysts, ${ }^{2}$ and ionic liquid, ${ }^{3}$ among others. ${ }^{4}$ The most conventional method for the synthesis of quaternary phosphonium salts is given by a nucleophilic substitution reaction of alkyl halides with tertiary phosphines. ${ }^{5}$ An alternative preparative approach to phosphonium salts via a radical pathway recently appeared. ${ }^{6}$ However, the phosphonium salts that are accessible by these methods are limited to those of acyclic structures. It presents a challenge to develop a facile method to synthesize phosphonium salts of cyclic structures from readily available starting substances. Herein reported is a photocatalytic cycloaddition reaction of triarylphosphines with alkynes. The phosphonium salts of unique bicyclic structures were synthesized from those readily available starting materials.

Conventional method
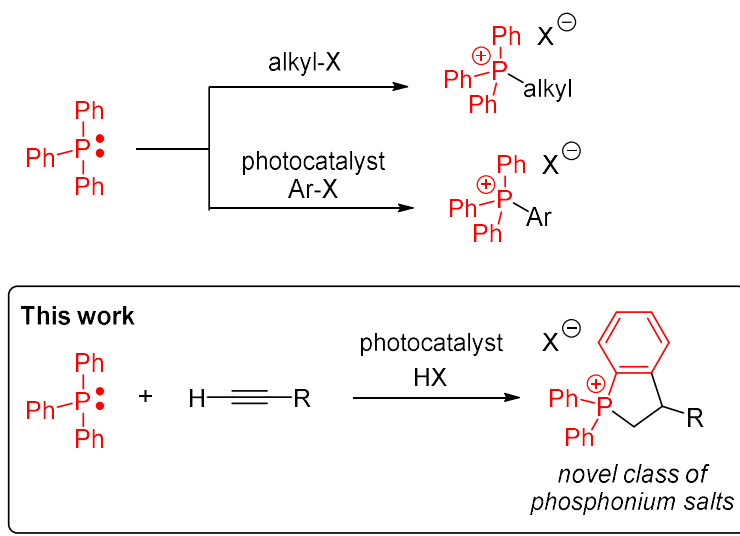

Figure 1. Syntheses of phosphonium salts.

We recently reported a three component coupling reaction of triarylphosphines, alkenes, and water. ${ }^{7}$ It was formation and dearomatization of the phenyl ring. We next examined an analogous reaction using an alkyne instead of an alkene; a mixture of triphenylphosphine (1), alkyne 2 49
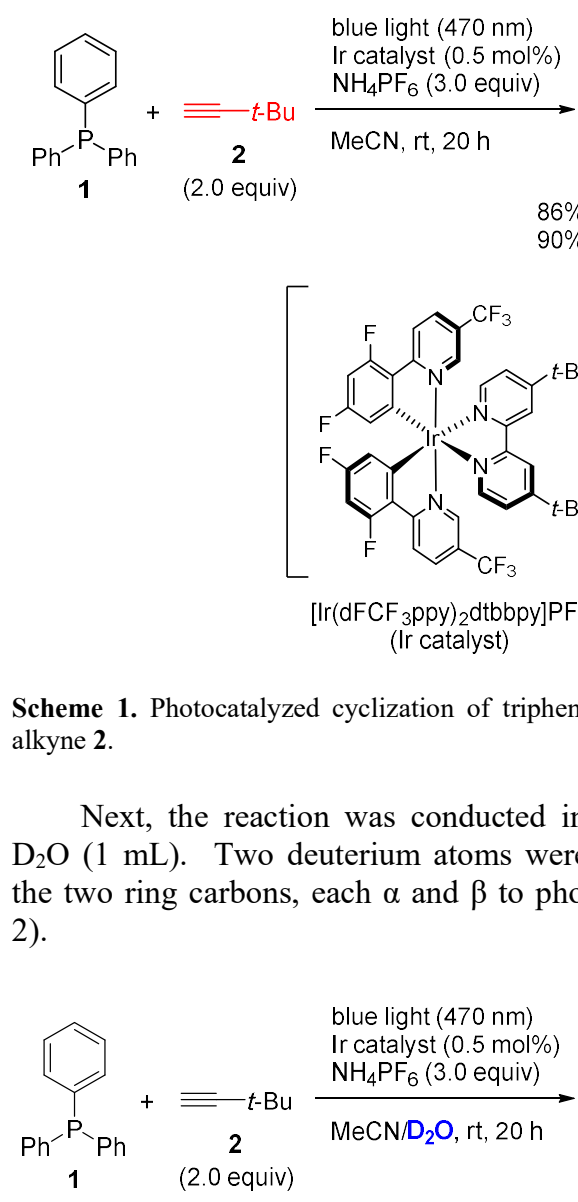
alkyne 2 . 2).
(2.0 equiv), ammonium hexafluorophosphate $\left(\mathrm{NH}_{4} \mathrm{PF}_{6}, 3.0\right.$ equiv), and an iridium photocatalyst ( $\left.\operatorname{Ir}\left(\mathrm{dFCF}_{3} \text { ppy }\right)_{2} \mathrm{dtbbpy}_{\mathrm{PF}_{6}}, 0.5 \mathrm{~mol} \%\right)$ in acetonitrile was irradiated with blue light $(470 \mathrm{~nm})$ for $20 \mathrm{~h}$, and the reaction mixture was subjected to chromatographic purification on silica gel. To our surprise, the phosphonium salt having a bicyclic structure 3 was obtained in $86 \%$ isolated yield (Scheme 1). The structure of 3 was confirmed by an X-ray crystallographic analysis (CCDC 2084056). In a formal sense, [3+2]-type cycloaddition took place to construct the five-membered ring. Light, $\mathrm{NH}_{4} \mathrm{PF}_{6}$, and the iridium catalyst were all indispensable for the production of 3 . $^{8}$ When the reaction was scaled up to a $4.0 \mathrm{mmol}$ scale, the product 3 could be isolated by recrystallization in place of chromatography, and its yield improved to $90 \%$.

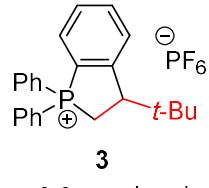

$86 \%$ on $0.2 \mathrm{mmol}$ scale $90 \%$ on $4.0 \mathrm{mmol}$ scale

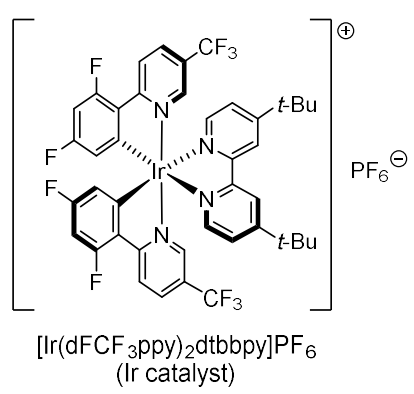

Scheme 1. Photocatalyzed cyclization of triphenylphosphine (1) and

Next, the reaction was conducted in the presence of $\mathrm{D}_{2} \mathrm{O}(1 \mathrm{~mL})$. Two deuterium atoms were incorporated on the two ring carbons, each $\alpha$ and $\beta$ to phosphorus (Scheme

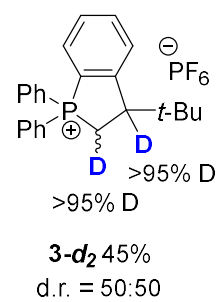


1 Scheme 2. Reaction in the presence of $\mathrm{D}_{2} \mathrm{O}$.

We propose a reaction pathway shown in Scheme 3 to 3 explain the formation of $\mathbf{3}$ from $\mathbf{1}$ and $\mathbf{2}$. Initially, the 4 iridium(III) catalyst absorbs light to get excited. 5 Triphenylphosphine (1) $\left(\mathrm{E}_{1 / 2}{ }^{\mathrm{red}}=+0.98 \mathrm{~V}\right.$ vs $\mathrm{SCE}$ in

$\left.6 \mathrm{CH}_{3} \mathrm{CN}\right)^{9}$ transfers a single electron to the excited 7 iridium(III) catalyst $\left(\mathrm{E}_{1 / 2}{ }^{\text {red }}[\operatorname{Ir}(\mathrm{III}) * / \mathrm{Ir}(\mathrm{II})]=+1.21 \mathrm{~V}\right.$ vs SCE 8 in $\left.\mathrm{CH}_{3} \mathrm{CN}\right),{ }^{10}$ generating radical cation $\mathbf{A}$ and an iridium(II) 9 species. The phosphine radical cation $\mathbf{A}$ adds across the $\mathrm{C}-$ $10 \mathrm{C}$ triple bond of $\mathbf{2}$ to generate substituted alkenyl radical $\mathbf{B}$, 11 which adds onto the phenyl ring to form the five-membered 12 ring. The resulting cyclohexadienyl radical $\mathbf{C}$ accepts a 13 single electron from the iridium(II) species to become the 14 cyclohexadienyl anion $\mathbf{D}$, the anionic charge of which is 15 delocalized onto the attached cationic phosphorus, thereby 16 regenerating the iridium(III) catalyst. The following 1,317 prototropic shift extends delocalization even further, giving 18 rise to the conjugated alkene $\mathbf{E}$. Finally, aromaticity is 19 regained upon protonation at the carbon $\beta$ to the phosphorus 20 atom to furnish the bicyclic phosphonium salt 3 .
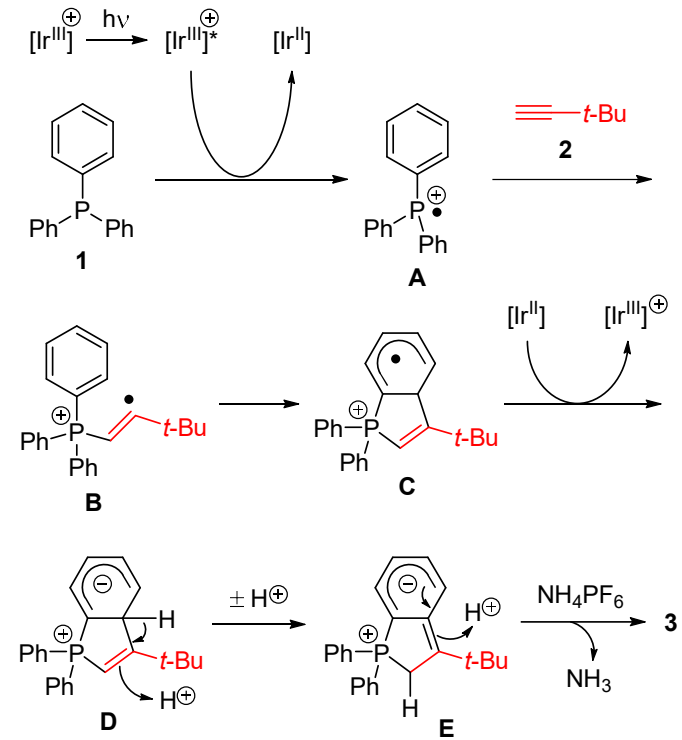

23 Scheme 3. A proposed reaction pathway.
Other triarylphosphines than $\mathbf{1}$ were also examined. Functional groups such as fluoro (11) and methoxy (12) groups were tolerated on the aromatic ring of triarylphosphines. Not only triarylphosphines but also methyldiphenylphosphine participated in the cycloaddition reaction with alkyne. The cyclic phosphonium salt $\mathbf{1 3}$ was produced in $97 \%$ yield as a mixture of diastereomers.

Table 1. Substrate scope. ${ }^{a}$

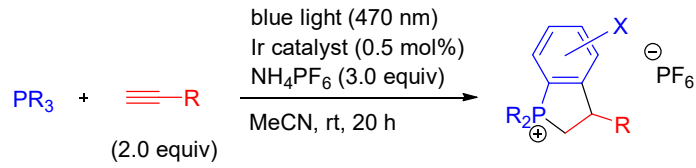

scope with respect to alkynes

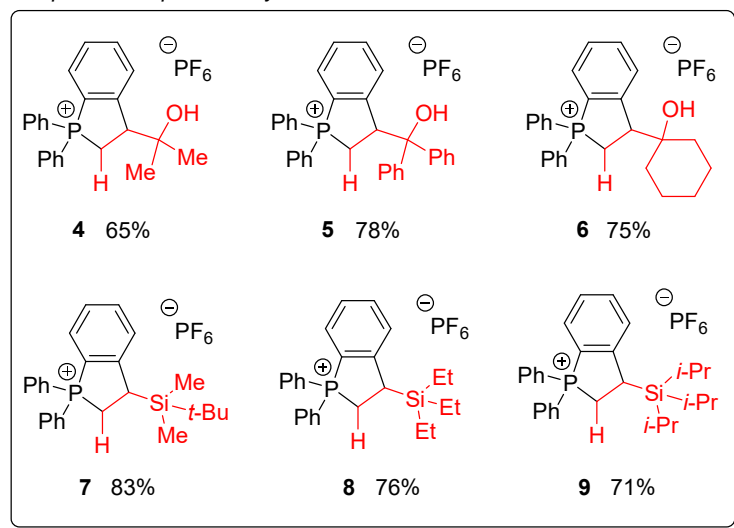

scope with respect to tertiary phosphines

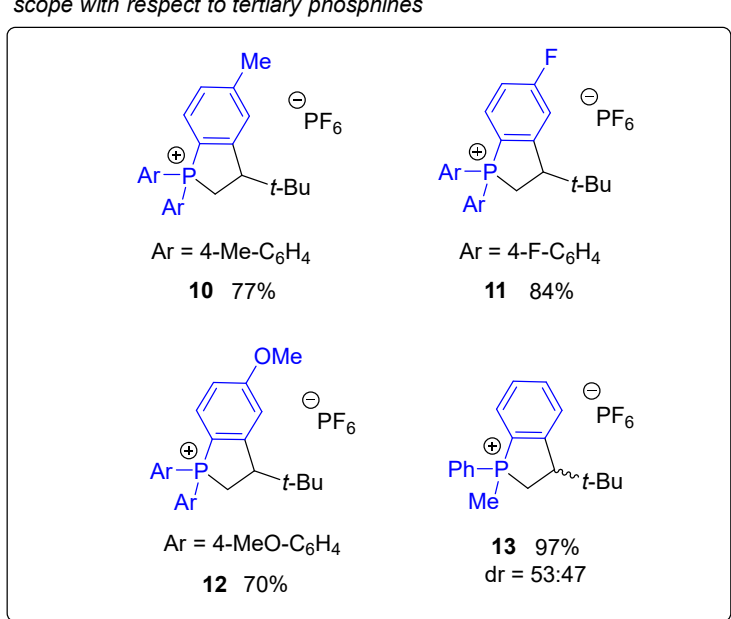

a Reaction conditions: tertiary phosphine $(0.20 \mathrm{mmol})$, alkene $(0.40$ mmol, 2.0 equiv), $\mathrm{NH}_{4} \mathrm{PF}_{6}(0.60 \mathrm{mmol}, 3.0$ equiv), Ir catalyst $(0.001$ mmol, $0.5 \mathrm{~mol} \%)$, MeCN (3 mL), blue LEDs (470 nm), rt, $20 \mathrm{~h}$. Isolated yield.

It was possible to convert the produced phosphonium salts to the corresponding phosphine oxides according to a literature procedure, ${ }^{11}$ the phosphonium salt 3 was treated with $\mathrm{NaOH}$ in $\mathrm{THF} /$ water at room temperature for $3 \mathrm{~h}$. $\mathrm{P}(\mathrm{III})^{+}$was oxidized to $\mathrm{P}(\mathrm{V})=\mathrm{O}$ and the phenyl substituent on it was protonated to afford benzophospholane oxide $\mathbf{1 4}$ in $86 \%$ yield as a single diastereomer. 
<smiles>CC1C(C(C)(C)C)c2ccccc2[PH]1(c1ccccc1)c1ccccc1</smiles>

2 Scheme 4. Derivatization of the produced phosphonium salts.

3

4

5

6

7

8

9

10

12

The phosphonium salts were used in the Wittig olefination reaction (Table 2). After a solution of the phosphonium salt 3 in tetrahydrofuran (THF) was treated with lithium diisopropylamide (LDA, 1.3 equiv) at $-78^{\circ} \mathrm{C}$ for $1 \mathrm{~h}$, benzaldehyde (2.0 equiv) was added to the generated ylide, and the reaction mixture was stirred at room temperature for $12 \mathrm{~h}$. The corresponding alkenylated phosphine oxide 15 was obtained in $79 \%$ yield. A high $Z$ selectivity $(Z / E>95 / 5)$ was observed, as is often the case with the Wittig reaction of unstable ylides. ${ }^{12}$ Not only benzaldehyde but also octanal served as an aldehyde to furnish the alkene $\mathbf{1 8}$ in $57 \%$ yield. Cinnamyl aldehyde produced 1,3-diene 19 in $73 \%$ yield. Of note is that the phosphine oxide moiety remaining in the product is amenable to further transformation. ${ }^{13}$

Table 2. Wittig-type coupling of phosphonium salt 3 with aldehydes. ${ }^{a}$

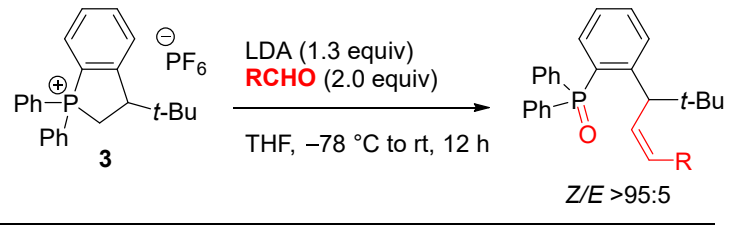

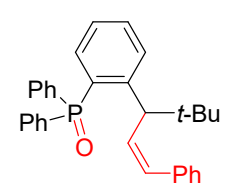

$1579 \%$
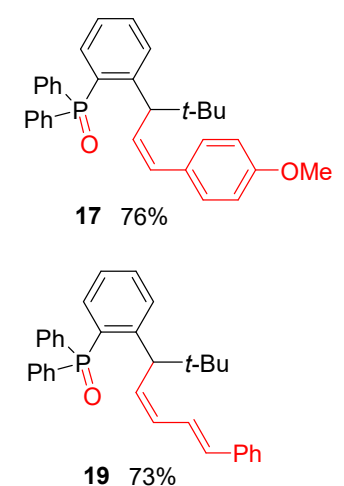

21
In conclusion, the present study discloses a new synthetic approach to the phosphonium salts of unique cyclic structures starting from tertiary phosphines and alkynes, which are both readily available. The produced phosphonium salts are engaged in the Wittig olefination reaction to afford the corresponding phosphine oxides of interesting structures.

This work was supported by JSPS KAKENHI Grant Numbers 19K15562 and 21K14626 (Y.M.).

Supporting Information is available on $\mathrm{http} / / / \mathrm{dx}$. doi.org/10.1246/cl.******.

\section{References and Notes}

1 a) Modern Carbonyl Olefination-Methods and Applications (Ed: T. Takeda), Wiley-VCH, Weinheim, 2004. b) M. Sakamoto, I. Shimizu, A. Yamamoto, Chem. Lett. 1995, 24, 1101-1102.

2 For selected reviews, see: a) T. Werner, Adv. Synth. Catal. 2009, 351, 1469-1481. b) D. Enders, T. V. Nguyen, Org. Biomol. Chem. 2012, 10, 5327-5331. c) S. Liu, Y. Kumatabara, S. Shirakawa, Green Chem. 2016, 18, 331-341. (d) A. Golandaj, A. Ahmad, D. Ramjugernath, Adv. Synth. Catal. 2017, 359, 36763706. For selected examples, see: e) D. Uraguchi, S. Sakaki, T. Ooi, J. Am. Chem. Soc. 2007, 129, 12392-12393. f) R. He, C. Ding, K. Maruoka, Angew. Chem. Int. Ed. 2009, 48, 4559-4561. g) Y. Toda, Y. Komiyama, A. Kikuchi, H. Suga, ACS Catal. 2016, 6, 6906-6910.

3 a) J. McNulty, J. J. Nair, S. Cheekoori, V. Larichev, A. Capretta, A. J. Robertson, Chem. Eur. J. 2006, 12, 9314-9322. b) H. Cao, L. McNamee, H. Alper, J. Org. Chem. 2008, 73, 3530-3534. c) Y. Kunugi,_H. Hayakawa, K. Tsunashima, M. Sugiya, Bull. Chem. Soc. Jpn. 2007, 80, 2473-2475. d) C. G. Cassity, A. Miriafari, N. Mobarrez, K. J. Strickland, R. A. O'Brien, J. H. Davis, Jr., Chem. Commun. 2013, 49, 7590-7592.

4 Selected examples, see: a) D. C. Rideout, A. Bustmante, J. Patel, Int. J. Cancer 1994, 57, 247. b) R. A. J. Smith, C. M. Porteous, A. M. Gane, M. P. Murphy, Proc. Natl. Acad. Sci. U. S. A. 2003, 100, 5407. c) K. Tanaka, H. Itoh, A. Nakashima, D. Wójcik, Z. Urbanczyk-Lipkowska, Bull. Chem. Soc. Jpn. 2009, 82, 489-493. d) W. Wan, X. Yang, R. C. Smith, Chem. Commun. 2017, 53, 252- 254. e) A. H. Nahlé, T. J. Harvey, F. C. Walsh, J. Alloys Compd. 2018, 765, 812-825. f) R. D. Dolewski, M. C. Hilton, A. McNally, Synlett, 2018, 29, 8-14.

5 a) T. Migita, T. Nagai, K. Kiuchi, M. Kosugi, Bull. Chem. Soc. Jpn. 1983, 56, 2869-2870. b) D. Marcoux, A. B. Charette, $A d v$. Synth. Catal. 2008, 350, 2967-2974. c) D. Marcoux, A. B. Charette, J. Org. Chem. 2008, 73, 590-593. d) E. Rémond, A. Tessier, F. R. Leroux, J. Bayardon, S. Jugé, Org. Lett. 2010, 12, 1568-1571. e) W. Huang, C.-H. Zhong, ACS Omega 2019, 4, 6690-6696.

6 a) A. F. Fearnley, J. An, M. Jackson, P. Lindovska, R. M. Denton, Chem. Commun. 2016, 52, 4987-4990. b) D. I. Bugaenko, A. A. Volkov, M. V. Livantsov, M. A. Yurovskaya, A. V. Karchava, Chem. Eur. J. 2019, 25, 12502-12506. c) P. Beatrice Arockiam, U. Lennert, C. Graf, R. Rothfelder, D. J. Scott, T. G. Fischer, K. Zeitler, R. Wolf, Chem. Eur. J. 2020, 26, 16374-16382. d) V. V. Levin, A. D. Dilman, Chem. Commun. 2021, 57, 749-752.

7 Y. Masuda, H. Tsuda, M. Murakami, Angew. Chem. Int. Ed. 2021, 60, 3551-3555.

8 Other proton sources than $\mathrm{NH}_{4} \mathrm{PF}_{6}$, such as ammonium chloride and acetic acid, gave $\mathbf{3}$ in lower yields. 
19 G. Pandey, D. Pooranchand, U. T. Bhalerao, Tetrahedron 1991, 47, 1745-1752.

10 M. S. Lowry, J. I. Goldsmith, J. D. Slinker, R. Rohl, R. A. Pascal, Jr., G. G. Malliaras, S. Bernhard, S. Chem. Mater. 2005, 17, $5712-5719$.

11 For hydrative dearylation of arylphosphonium salts, see: a) W. E. McEwen, K. F. Kumli, A. Blade-Font, M. Zanger, C. A. VanderWerf, J. Am. Chem. Soc. 1964, 86, 2378-2384. b) J. R. Corfield, S. Trippett, J. Chem. Soc. Chem. Commun. 1970, 1267-1276. c) A. Schnell, J. C. Tebby, J. Chem. Soc. Perkin Trans. 1 1977, 1883-1886.

12 P. A. Byrne, D. G. Gilheany, Chem. Soc. Rev. 2013, 42, 66706696.

13 a) J. M. Muchowski, M. C. Venuti, J. Org. Chem. 1981, 46, 459461. b) I. Yamamoto, S. Tanaka, T. Fujimoto, K. Ohta, J. Org. Chem. 1989, 54, 747-750. 
NOTE The diagram is acceptable in a colored form. Publication of the colored G.A. is free of charge.

For publication, electronic data of the colored G.A. should be submitted. Preferred data format is EPS, PS, CDX, PPT, and TIFF.

If the data of your G.A. is "bit-mapped image" data (not "vector data"), note that its print-resolution should be 300 dpi.

You are requested to put a brief abstract (50-60words, one paragraph style) with the graphical abstract you provided, so that readers can easily understand what the graphic shows.

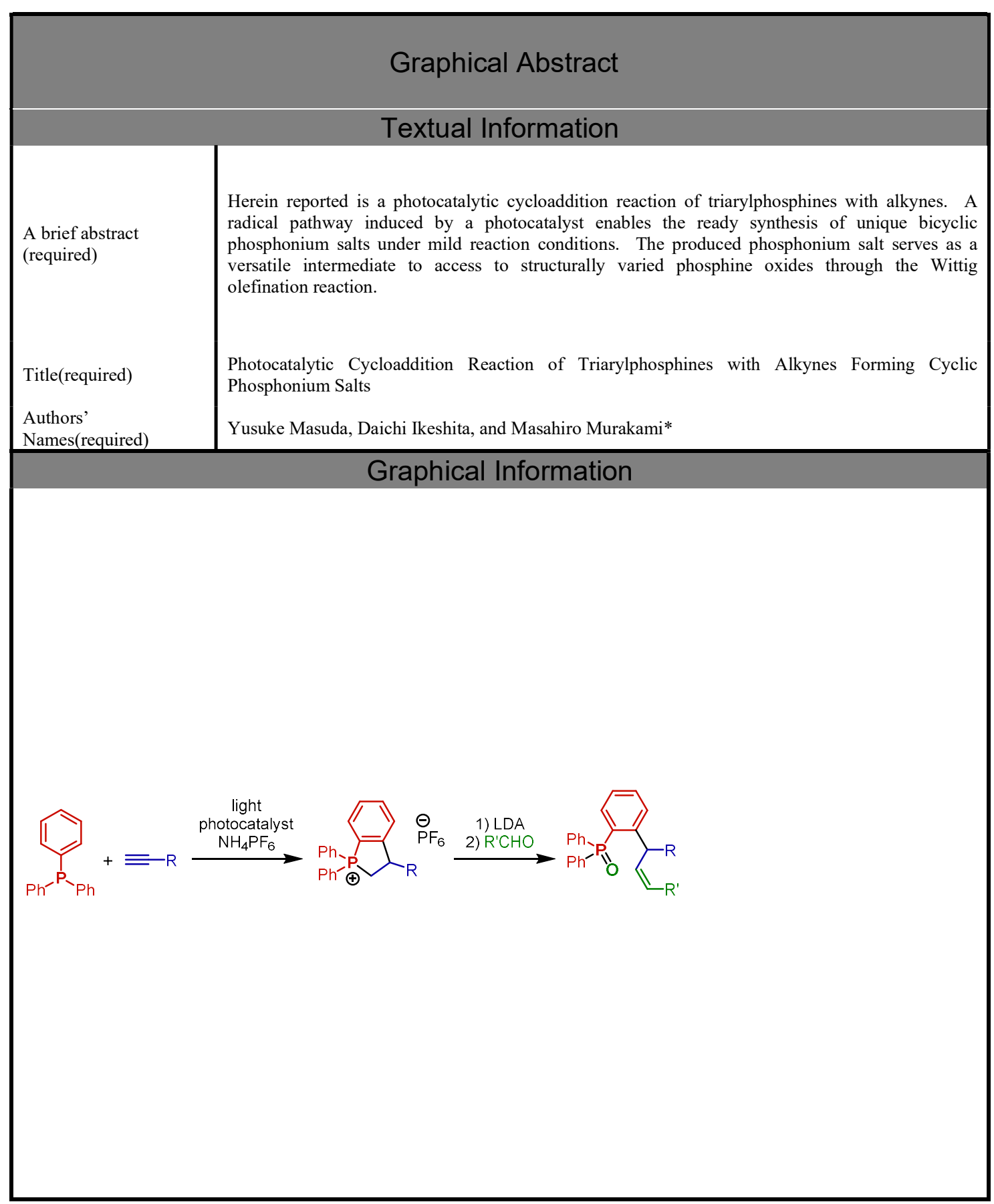

